\title{
Multidimensional assessment of personality in patients with psychogenic non-epileptic seizures
}

\author{
M Reuber, R Pukrop, J Bauer, R Derfuss, C E Elger
}

See Editorial Commentary, p 667

J Neurol Neurosurg Psychiatry 2004;75:743-748. doi: 10.1136/jnnp.2003.013821

See end of article for

authors' affiliations

....................

Correspondence to:

Dr Markus Reuber,

Academic Unit of

Neurology, Division of

Genomic Medicine,

University of Sheffield,

Royal Hallamshire

Hospital, Glossop Road,

Sheffield S10 2JF, UK;

mreuber@doctors.org.uk

Received 28 February 2003

In revised form

29 July 2003

Accepted 4 August 2003

Objectives: To determine whether patients with psychogenic non-epileptic seizures (PNES) have evidence of maladaptive personality, and whether they have a single or several different typical pathological personality profiles.

Methods: Patients were recruited from the department of epileptology, Bonn, Germany. In all, 85 patients with PNES and 63 with epilepsy completed a postal questionnaire including the dimensional assessment of personality pathology - basic questionnaire (DAPP-BQ). The DAPP-BQ was also completed by 100 healthy volunteers. The groups were compared and the PNES group was subjected to cluster analysis.

Results: Patients with PNES had a greater degree of personality abnormality than clinical and non-clinical controls. There were several clusters of personality pathology. The profile of the largest cluster $(n=43)$ resembled that found in borderline personality disorder, that of the second largest $(n=37)$ was characterised by an overly controlled personality, that of the third $(n=4)$ was similar to the profile in avoidant personality disorder. Outcome differed between clusters.

Conclusions: Maladaptive personality is common in patients with PNES. PNES are associated with several distinct profiles of pathological personality. This is relevant because outcome differed between profiles.

$\mathrm{P}$ sychogenic non-epileptic seizures (PNES) are episodes of altered movement, sensation, or experience similar to epilepsy. However, they are not associated with abnormal electrical discharges in the brain but are caused by a psychological process. ${ }^{1}$ The psychophysiological mechanisms that cause PNES are controversial, ${ }^{2}$ and so is the question of how PNES should be categorised in psychiatric terms. ${ }^{3}$ In contrast, there is general agreement that abnormal personality traits or personality disorder are commonly associated with PNES, and that they are relevant to outcome. ${ }^{4-7}$

Despite this, there have been only a few studies examining personality in this patient group using tools providing a systematic representation of personality and personality disorder. Most previous studies were based on the Minnesota multiphasic personality inventory (MMPI). ${ }^{8-14}$ However, the MMPI is difficult to interpret because it not only measures personality characteristics but also psychopathological syndromes such as hypochondriasis, conversion disorder, depression, schizophrenia, fear, and others. Moreover, the $\kappa$ value of the median convergent validity between personality disorder diagnoses obtained by the MMPI and the structured clinical interview for Diagnostic and Statistical Manual of Mental Disorders, fourth edition (DSMIV) ${ }^{15}$ for Axis-II is only 0.20 (range -0.05 to 0.42 )..$^{16}$

Other studies have used clinical diagnoses of personality disorder based on DSM-IV criteria. ${ }^{6}$ However, there is accumulating empirical evidence that disorders of personality are poorly characterised by the categorical approach used in the DSM systems, with their considerable symptomatic and behavioural overlap between different types of personality disorder and their poor interobserver reliability. It is becoming increasingly clear that personality is more appropriately described by a dimensional trait model that considers personality disorders as maladaptive or extreme variants of common personality traits which merge imperceptibly into normality and into one another..$^{17}$

Our aim in this study was to address the issue of personality in patients with PNES, using the dimensional assessment of personality pathology - basic questionnaire
(DAPP-BQ $)^{19}$; this assesses 18 traits and four higher order dimensions of personality pathology extracted from the intercorrelations of 100 self report scales of traits identified from published reports and by clinical judgement (examples shown in table 1). ${ }^{20}$ The DAPP-BQ profile has been found to be stable across psychiatric and non-clinical samples, and is congruent for environmental, genetic, and phenotypic factors derived from twin studies. ${ }^{21}$ The instrument has been shown to distinguish between normal controls, patients with borderline personality disorder (according to DSM-IV criteria), and patients with other personality disorders. ${ }^{22}$ It also provides characteristic personality profiles for the DSM-IV axis II categories. ${ }^{23}$

The dimensional structure of personality pathology described by the DAPP-BQ is in accordance with the most important contemporary approach to normal personality, the five factor model developed by Costa and McCrae. ${ }^{24}$ The "Big Five" dimensions-“neuroticism," "extraversion," "agreeableness," "conscientiousness," and "openness to experience" - have been shown to be necessary and sufficient to provide a comprehensive description of human personality almost independent of cultural background. ${ }^{25} 26$

By comparing personality traits in patients with PNES with two control groups (a group of healthy volunteers and a group of patients with epilepsy), we examined whether maladaptive personality is more common in patients with PNES, and whether personality was more abnormal in individuals with PNES than in those with epilepsy. By subsequent cluster analysis within the PNES group, we assessed whether there are one or several personality profiles characteristic of patients with psychogenic seizures.

\footnotetext{
Abbreviations: $D A P P-B Q$, dimensional assessment of personality pathology - basic questionnaire; DSM-IV, Diagnostic and Statistical Manual of Mental Disorders, fourth edition; GNS, general neurotic syndrome; MMPI, Minnesota multiphasic personality inventory; PNES, psychogenic non-epileptic seizures
} 


\begin{tabular}{|c|c|c|}
\hline Higher order dimension & Lower order trait & Typical item \\
\hline Emotional dysregulation & $\begin{array}{l}\text { Anxiousness } \\
\text { Identity problems } \\
\text { Social avoidance } \\
\text { Affective lability } \\
\text { Cognitive distortion } \\
\text { Oppositionality } \\
\text { Submissiveness } \\
\text { Insecure attachment } \\
\text { Self harm } \\
\text { Suspiciousness } \\
\text { Narcissism }\end{array}$ & $\begin{array}{l}\text { I am always worrying about something } \\
\text { I am unsure of what kind of person I really am } \\
\text { I avoid people whenever possible } \\
\text { I often feel as if I am on an emotional roller-coaster } \\
\text { I have felt that things around me have seemed unreal } \\
\text { I often don't do things that I am supposed to do } \\
\text { If I am pressured, I will usually give in } \\
\text { I feel panicky when I am separated from those I love } \\
\text { Ending my life sometimes seems the only way out } \\
\text { I think that other people are always trying to cheat me } \\
\text { I really need to know that people aporove of me }\end{array}$ \\
\hline Dissocial behaviour & $\begin{array}{l}\text { Stimulus seeking } \\
\text { Conduct problems } \\
\text { Rejection } \\
\text { Callousness }\end{array}$ & $\begin{array}{l}\text { When I take risks, I never worry about getting hurt } \\
\text { When rules are inconvenient, I break them } \\
\text { I like to challenge people }\end{array}$ \\
\hline Inhibitedness & $\begin{array}{l}\text { Intimacy problems } \\
\text { Restricted expression }\end{array}$ & $\begin{array}{l}\text { I rarely, if ever, become sexually excited } \\
\text { I don't often show my feelings }\end{array}$ \\
\hline Compulsivity & & I try to keep everything in its proper place \\
\hline
\end{tabular}

Users are asked to judge each statement as "very unlike me," "moderately unlike me," "somewhat like and unlike me," "moderately like me," or "very like me" for 16 items in each trait.

\section{METHODS \\ Patients with PNES}

The computerised database of the department of epileptology at the University of Bonn, Germany, was used to identify all patients in whom a diagnosis of PNES was established between April 1991 and April $2001(\mathrm{n}=329)$. The diagnosis was considered "established" if it had been secured by the documentation of spontaneous events with video-electroencephalography (EEG), EEG, observation, and ictal examination, or by the provocation of a typical seizure by suggestive intravenous injection of $0.9 \%$ saline under videoEEG surveillance. Patients were excluded if there was evidence of concurrent or previous epilepsy $(n=119)$. The additional diagnosis of epilepsy was based on ictal EEG or video-EEG recordings (66/119), or the clinical assessment of an experienced epileptologist (53/119). Patients were also excluded if epileptiform potentials were seen in interictal EEGs $(n=13)$. Biographical information and details of medical and seizure history were retrieved retrospectively from clinical records.

\section{Patients with epilepsy}

The epilepsy group consisted of 119 consecutive patients who were admitted to our ward between 1 January and 4 August 1995, during the middle of the recruitment period for the PNES group. Patients were admitted for evaluation for epilepsy surgery $(n=61)$, the establishment of a clear diagnosis $(n=42)$, reassessment of epilepsy treatment $(n=14)$, or in status epilepticus $(n=2)$. No PNES were observed in these patients with epilepsy and none had a history suggestive of additional PNES.

\section{Healthy controls}

A healthy control sample of 100 subjects comprising 80 women and 20 men was recruited from staff members, their friends and relatives, and from the university campus.

\section{Personality traits}

PNES and epilepsy patients were approached by post and asked to return a completed copy of the DAPP-BQ. A reminder note was sent to non-responders after three weeks. The DAPP-BQ is a 290 item self report measure with five response categories for each item. The items can be summed up to 18 scales of lower order traits which make up four higher order dimensions (see table 1). ${ }^{1921}$ Internal consistency ranges from 0.83 to 0.94 , and test-retest reliability over a three week period from 0.81 to $0.93 .{ }^{21}$ The German version of the DAPP-BQ was developed by the author of the original version and the department of psychology of the University of Bielefeld, Germany, using a forward-backward method, and has been validated in different psychiatric patient groups and healthy controls. ${ }^{26}$ The first higher order dimension labelled "emotional dysregulation" (resembling the Big Five factor "neuroticism") represents unstable and reactive tendencies, dissatisfaction with the self and life experiences, and interpersonal problems. The following lower order traits were consistently found to have their highest loading on this dimension: anxiousness, identity problems, social avoidance, affective lability, cognitive dysfunction, oppositionality, submissiveness, insecure attachment, and self harm. The second higher order dimension labelled "dissocial behaviour" (resembling the negative pole of the Big Five factor "agreeableness") represents a lack of regard for others. This dimension was consistently marked by the traits stimulus seeking (sensation seeking, impulsivity, and recklessness), conduct problems, rejection (interpersonal hostility and judgmental attitudes), and callousness. The third higher order dimension labelled "inhibitedness" (resembling the negative pole of "extraversion") represents little enjoyment from intimate relationships, and was consistently defined by the traits "intimacy problems" and "restricted expression" (restricted expression of affect and difficulties in sharing information). The fourth higher order dimension labelled "compulsivity" (resembling the Big Five factor "conscientiousness") was consistently marked by the trait "compulsivity." The lower order traits "suspiciousness" and "narcissism" showed relations to both emotional dysregulation and dissocial behaviour. See table 1 for the structure of the DAPP-BQ profile. In the development of the DAPP-BQ, no personality component resembling the Big Five factor "openness to experience" was found to be relevant for clinical samples.

\section{Statistical analysis}

DAPP-BQ scores in 18 lower and four higher order traits were compared between the groups (PNES $v$ epilepsy patients $v$ healthy controls) by one way analysis of variance (ANOVA), with Bonferroni posthoc tests. Only probability $(p)$ values of 0.005 or less were considered to indicate a relevant difference between groups, to reduce the risk of chance findings owing to the large number of comparisons. To determine whether there are one or several typical PNES personality profiles, DAPP-BQ scores within the PNES group were further assessed by cluster analysis. Cluster membership of cases 
was calculated using the average linkage method, and the number of clusters was determined by a significant increase in the error sum of squares. Clusters and healthy controls were compared by one way ANOVA, $\chi^{2}$ test, Mann-Whitney U test, or Student's $t$ test as appropriate.

\section{RESULTS}

\section{Responders/non-responders}

Of the 197 patients with PNES, 85 (43.1\%) returned the postal questionnaire, $57(28.9 \%)$ could not be traced, four $(2.0 \%)$ did not want to take part, and 51 (25.9\%) failed to return the questionnaire. Five PNES patients with recognised learning disability were able to complete the questionnaire. The rate of evaluated responses from PNES patients who could be contacted was therefore $60.7 \%$. Responders did not differ from non-responders with regard to age at the time of manifestation of PNES, age at diagnosis, latency from manifestation to diagnosis, age at receipt of questionnaire, PNES frequency at presentation, sex, or length of follow up since the diagnosis. Of the 119 patients with epilepsy, 64 $(53.8 \%)$ returned the questionnaire, $31 \quad(26.1 \%)$ were untraceable, four $(3.4 \%)$ had died since their inpatient assessment, three $(2.5 \%)$ were unable to complete the questionnaire because of learning disabilities or language difficulties (two patients with epilepsy and recognised learning disability did complete the questionnaire), one $(0.8 \%)$ did not want to take part, and $16(13.4 \%)$ did not send back the questionnaire. The proportion of evaluated responses from those patients who were contactable was therefore $76.1 \%$.

\section{Patients}

Of the 85 responders in the PNES group, 70 (82.3\%) were female. The mean (SD) age of the group at the time of the study was 37.1 (15.8) years; their mean age at PNES onset was 26.8 (14.8) years, and their mean age at diagnosis, 33.8 (15.2) years. Sixty four $(75.3 \%)$ had been treated with anticonvulsant drugs. The patients responded to the postal questionnaire a mean of 3.7 (3.1) years after the diagnosis had been made.

Of the 63 responders in the epilepsy group, 24 (38.1\%) were female. Their mean age was 38.8 (10.1) years, and their mean age at the onset of epilepsy was 15.2 (10.9) years. These patients completed the questionnaire a mean of $6.0(0.2)$ years after inpatient assessment.

\section{Healthy controls}

The mean age of healthy controls was 36.4 (15.6) years (range 17 to 78 ). There were no significant differences between healthy controls and patients with PNES with respect to age $(t=1.036 ; \mathrm{p}=0.672)$ or $\operatorname{sex}\left(\chi^{2}=0.684\right.$; $\mathrm{p}=0.711)$.

\section{Personality: PNES v controls}

PNES patients had higher emotional dysregulation scores than the healthy and epileptic control groups $(\mathrm{p}<0.001)$. The PNES group scores on dissocial behaviour $(p=0.009)$, inhibitedness $(p<0.001)$, and compulsivity $(p<0.001)$ differed from the healthy controls only, and not from the epilepsy group. For details of the scores of the lower order traits that make up the four higher order dimensions, see table 2. There was no significant difference in an additional lie score between the three groups.

\section{Cluster analysis within the PNES group}

Cluster analysis revealed four identifiable subgroups within the PNES group. Cluster $1 \quad(n=43)$ was characterised by scores that were significantly higher than those of nonclinical controls in all of the four higher order dimensions of the DAPP-BQ. Such a broad increase in scores has previously been found in patients with the DSM-IV diagnosis of borderline personality disorder. ${ }^{22}$ Cluster 2 patients $(n=37)$ had increased compulsivity scores but normal scores in the higher order dimensions "emotional dysregulation," "dissocial behaviour," and "inhibitedness." This pattern of abnormality is similar to that seen in patients with compulsive personality disorder. ${ }^{22}$ Cluster 3 patients $(n=4)$ had increased emotional dysregulation, inhibitedness, and compulsivity but not dissocial behaviour scores. This pattern most closely resembles that associated with avoidant personality disorder. ${ }^{22}$ Cluster 4 consisted only of a single patient, who was considered an outlier and was excluded from further analyses. For details of the higher order profiles of the different clusters, see table 3.

\section{Lower order personality traits of major clusters compared with healthy controls}

Compared with non-clinical controls, cluster 1 patients showed a broad increase in all lower order trait scores except callousness and intimacy problems. Cluster 2 patients only showed increased rejection and compulsivity scores. The scores of all other traits in which cluster 2 patients differed from the non-clinical sample (anxiousness, self harm, suspiciousness, narcissism, and conduct problems) were lower than those of controls. Further details of the personality profiles of clusters 1 and 2 are given in table 4 .

\section{Clinical differences between major clusters}

Of the patients in cluster $1,83.7 \%$ continued to have PNES at follow up, and of those in cluster $2,59.5 \%\left(\chi^{2}=5.871\right.$, $\mathrm{p}=0.023)$. In cluster $1,48.8 \%$ of the patients had received psychiatric inpatient treatment, as opposed to $22.2 \%$ of cluster $2\left(\chi^{2}=6.404, p=0.018\right)$. The two clusters did not differ with respect to sex, duration of seizure disorder, history of seizure related injury, loss of consciousness, tongue biting or incontinence, history of inpatient treatment, emergency admission, intensive care treatment, or PNES status.

\section{DISCUSSION}

As a group, PNES patients had increased scores across all four higher order dimensions-emotional dysregulation, dissocial behaviour, inhibitedness, and compulsivity-when compared with healthy controls. While it should be pointed out that the difference in dissocial behaviour was entirely caused by higher scores on the rejection trait and not conduct problems (which were less pronounced in PNES patients than in healthy controls), this is a broad profile of personality pathology. Such a profile is in keeping with previous studies in PNES patients using other psychological tools. ${ }^{8}{ }^{10} 27$

To ensure that the observed abnormalities did not simply reflect the fact that the PNES group were experiencing seizures or that they were "patients," we also compared their personality profile with that of patients with epilepsy. This comparison still showed clear differences, but they were confined to the higher order dimension "emotional dysregulation." This broad dimension of personality pathology reflects stable personality vulnerabilities, which put individuals at greater risk of anxiety and depressive symptoms. This general diathesis, which has been termed "general neurotic syndrome" (GNS), ${ }^{28}$ is characterised by a combination of high trait anxiety/high arousability and poor coping. ${ }^{29}$ The differential increase in scores on the central traits of anxiousness and affective lability suggests that many PNES patients struggle to regulate emotional experience. The observation of these maladaptive personality traits in patients with a somatoform disorder would be consistent with the suggestion that, because personality disorder and somatoform disorders show syndromal comorbidity, begin early in 
Table 2 Scores of lower order traits in patients with psychogenic non-epileptic seizures (PNES), patients with epilepsy, and healthy controls

\begin{tabular}{|c|c|c|c|c|c|c|}
\hline Higher order dimension & Lower order trait & $\begin{array}{l}\text { PNES } \\
(n=85)\end{array}$ & $\begin{array}{l}\text { Healthy controls } \\
(n=100)\end{array}$ & $\begin{array}{l}\text { Epilepsy controls } \\
(\mathrm{n}=64)\end{array}$ & $\begin{array}{l}\text { PNES } v \text { healthy } \\
\text { controls }\end{array}$ & $\begin{array}{l}\text { PNES } v \text { epilepsy } \\
\text { controls }\end{array}$ \\
\hline \multirow[t]{11}{*}{ Emotional dysregulation } & Anxiousness & $3.0(0.8)$ & $3.0(0.6)$ & $2.5(0.8)$ & NS & $\mathrm{p}<0.001$ \\
\hline & Identity problems & $2.6(0.8)$ & $2.1(0.5)$ & $2.3(0.7)$ & $\mathrm{p}<0.001$ & $p=0.004$ \\
\hline & Social avoidance & $2.6(0.8)$ & $2.0(0.4)$ & $2.5(0.7)$ & $\mathrm{p}<0.001$ & NS \\
\hline & Affective lability & $3.0(0.7)$ & $2.5(0.6)$ & $2.6(0.7)$ & $\mathrm{p}<0.001$ & $\mathrm{p}<0.001$ \\
\hline & Cognitive distortion & $2.6(0.8)$ & $1.9(0.5)$ & $2.2(0.8)$ & $\mathrm{p}<0.001$ & $\mathrm{p}<0.001$ \\
\hline & Oppositionality & $2.5(0.6)$ & $2.4(0.6)$ & $2.3(0.6)$ & NS & NS \\
\hline & Submissiveness & $2.8(0.7)$ & $2.5(0.5)$ & $2.5(0.6)$ & NS & NS \\
\hline & Insecure attachment & $3.1(0.9)$ & $2.4(0.5)$ & $2.7(0.8)$ & $\mathrm{p}<0.001$ & $p=0.005$ \\
\hline & Self harm & $2.0(1.1)$ & $2.1(0.5)$ & $1.4(0.6)$ & NS & $\mathrm{p}<0.001$ \\
\hline & Suspiciousness & $2.6(0.7)$ & $2.6(0.6)$ & $2.4(0.7)$ & NS & NS \\
\hline & Narcissism & $2.5(0.8)$ & $2.4(0.4)$ & $2.4(0.7)$ & NS & NS \\
\hline \multirow{4}{*}{ Dissocial behaviour } & Stimulus seeking & $2.7(0.5)$ & $2.5(0.6)$ & $2.5(0.6)$ & NS & NS \\
\hline & Conduct problems & $1.6(0.4)$ & $2.3(0.7)$ & $1.7(0.5)$ & $\mathrm{p}<0.001$ & NS \\
\hline & Rejection & $2.5(0.5)$ & $1.5(0.4)$ & $2.6(0.5)$ & $\mathrm{p}<0.001$ & NS \\
\hline & Callousness & $2.1(0.4)$ & $2.1(0.5)$ & $2.2(0.5)$ & NS & NS \\
\hline \multirow{2}{*}{ Inhibitedness } & Intimacy problems & $2.5(0.7)$ & $2.4(0.5)$ & $2.3(0.6)$ & NS & NS \\
\hline & Restricted expression & $2.9(0.6)$ & $2.5(0.6)$ & $2.7(0.6)$ & $\mathrm{p}<0.001$ & NS \\
\hline Compulsivity & & $3.4(0.6)$ & $1.2(0.4)$ & $3.3(0.6)$ & $\mathrm{p}<0.001$ & NS \\
\hline
\end{tabular}

life, persist through much of adulthood, and are distributed along a continuum in the general population, somatisation would be more accurately conceptualised as evidence of personality pathology than an axis I diagnoses. ${ }^{30}$

The lower order traits "identity problems," "affective lability," "cognitive distortion" and "insecure attachment" (which all contribute to the higher order dimension of emotional dysregulation) differentiated patients with PNES from both non-clinical controls and clinical controls with epilepsy. It would be of interest to examine whether individuals with PNES share these traits with other patients with medically unexplained symptoms.

Further analysis within the PNES group showed that patients did not fall into one neat category but into at least three different subgroups with characteristic personality profiles (a fourth cluster was defined by a single outlier and is not considered further). The commonest profile (cluster 1; 50.6\% of patients) showed a broad pattern of maladaptive personality traits across all four higher order dimensions (tables 3 and 4 ). This most typical pattern resembles the profile seen in patients with borderline personality disorder profile or the GNS.22 ${ }^{31}$ Borderline patients are characterised by fears of abandonment, unstable and intense relationships, an unstable self image, impulsivity, self harming behaviour, affective instability, a feeling of emptiness, difficulty in controlling anger, and dissociative symptoms. Given the demonstrative character and refractory nature of borderline personality disorder, this observation is consistent with the fact that more patients belonging to cluster 1 than cluster 2 had undergone psychiatric inpatient treatment, and that fewer patients in cluster 1 than cluster 2 were seizure-free at follow up.

The most outstanding feature of cluster 2 (43.5\% of PNES patients) was that scores of some central lower order traits (anxiousness, self harm, suspiciousness, narcissism, and conduct problems) were significantly lower than those of non-clinical controls. This suggests a profile of personality not characterised by affective dysregulation but by the desire for strictly conforming, overly controlled behaviour. This is supported by the significant increase in compulsivity scores indicating a high sense for orderliness, precision, and conscientiousness.

The four patients of cluster 3 may represent a small number of multimorbid subjects who (compared with clusters 1 and 2) showed the highest scores on all higher order dimensions except "dissocial behaviour." This profile of high emotional dysregulation and inhibitedness, with missing aggressive or antagonistic tendencies, resembles the profile for avoidant personality disorder. Patients with this personality disorder are characterised by fears of rejection, will only enter friendships if they are accepted without criticism, withhold intimate feelings out of fear of being ridiculed, often feel rejected in social situations, have low self esteem, believe themselves inferior to others, are reluctant to engage in new activities out of fear of embarrassment, and may use somatic symptoms as a reason for avoiding new activities.

In comparison with healthy controls, all clusters showed increased scores on compulsivity, which may represent an important difference between patients with PNES and those

Table 3 Mean higher order DAPP-BQ scores of healthy controls and PNES patient clusters

\begin{tabular}{|c|c|c|c|c|c|}
\hline Higher order dimension & $\begin{array}{l}\text { Cluster } 1 \\
(n=43)\end{array}$ & $\begin{array}{l}\text { Cluster } 2 \\
(n=37)\end{array}$ & $\begin{array}{l}\text { Cluster } 3 \\
(n=4)\end{array}$ & $\begin{array}{l}\text { Cluster } 4^{*} \\
(\mathrm{n}=1)\end{array}$ & $\begin{array}{l}\text { Healthy controls } \\
(n=100)\end{array}$ \\
\hline Emotional dysregulation & $3.1(0.3)$ & $2.1(0.3)$ & $3.5(0.2)$ & 3.5 & $2.2(0.4)$ \\
\hline Dissocial behaviour & $2.4(0.4)$ & $2.1(0.3)$ & $1.9(0.2)$ & 1.6 & $2.1(0.3)$ \\
\hline Inhibitedness & $2.9(0.5)$ & $2.4(0.5)$ & $3.3(0.5)$ & 2.2 & $2.4(0.5)$ \\
\hline Compulsivity & $3.5(0.5)$ & $3.3(0.5)$ & $4.3(0.4)$ & 2.1 & $1.2(0.4)$ \\
\hline
\end{tabular}

Values are mean (SD).

*In view of the group size of 1, no p values were calculated. Scores more than 1 SD from the healthy control mean are italicised.

Scores in bold significantly different from healthy controls $(p<0.001)$

$D A P P-B Q$, dimensional assessment of personality pathology - basic questionnaire; PNES, psychogenic nonepileptic seizures. 
Table 4 Full DAPP-BQ personality (pathology) profiles of major PNES patient clusters and healthy controls

\begin{tabular}{|c|c|c|c|c|c|c|}
\hline Higher order dimension & Lower order trait & $\begin{array}{l}\text { Cluster } 1 \\
(n=43)\end{array}$ & $\begin{array}{l}\text { Cluster } 2 \\
(n=37)\end{array}$ & $\begin{array}{l}\text { Healthy } \\
\text { controls } \\
(n=100)\end{array}$ & $\begin{array}{l}\text { Difference cluster } 1 v \\
\text { healthy controls }\end{array}$ & $\begin{array}{l}\text { Difference cluster } 2 v \\
\text { healthy controls }\end{array}$ \\
\hline \multirow[t]{11}{*}{ Emotional dysregulation } & Anxiousness & $3.5(0.5)$ & $2.3(0.4)$ & $3.0(0.6)$ & $p<0.001$ & $\mathrm{p}<0.001$ \\
\hline & Identity problems & $3.1(0.5)$ & $1.9(0.5)$ & $2.1(0.5)$ & $p<0.001$ & NS \\
\hline & Social avoidance & $3.0(0.5)$ & $2.0(0.5)$ & $2.0(0.4)$ & $p<0.001$ & NS \\
\hline & Affective lability & $3.4(0.5)$ & $2.5(0.5)$ & $2.5(0.6)$ & $\mathrm{p}<0.001$ & NS \\
\hline & Cognitive distortion & $3.0(0.6)$ & $1.9(0.6)$ & $1.9(0.5)$ & $p<0.001$ & NS \\
\hline & Oppositionality & $2.8(0.5)$ & $2.2(0.5)$ & $2.4(0.6)$ & $p<0.001$ & NS \\
\hline & Submissiveness & $3.0(0.5)$ & $2.3(0.5)$ & $2.5(0.5)$ & $\mathrm{p}<0.001$ & NS \\
\hline & Insecure attachment & $3.5(0.6)$ & $2.4(0.7)$ & $2.4(0.5)$ & $p<0.001$ & NS \\
\hline & Self harm & $2.4(1.1)$ & $1.2(0.5)$ & $2.1(0.5)$ & $p=0.032$ & $\mathrm{p}<0.001$ \\
\hline & Suspiciousness & $3.0(0.5)$ & $2.1(0.4)$ & $2.6(0.6)$ & $p<0.001$ & $\mathrm{p}<0.001$ \\
\hline & Narcissism & $2.9(0.7)$ & $2.1(0.5)$ & $2.4(0.4)$ & $p<0.001$ & $p=0.001$ \\
\hline \multirow[t]{4}{*}{ Dissocial behaviour } & Stimulus seeking & $2.9(0.5)$ & $2.5(0.5)$ & $2.5(0.6)$ & $p=0.001$ & NS \\
\hline & Conduct problems & $1.8(0.5)$ & $1.4(0.3)$ & $2.3(0.7)$ & $p<0.001$ & $\mathrm{p}<0.001$ \\
\hline & Rejection & $2.7(0.5)$ & $2.4(0.5)$ & $1.5(0.4)$ & $p<0.001$ & $\mathrm{p}<0.001$ \\
\hline & Callousness & $2.3(0.4)$ & $2.0(0.4)$ & $2.1(0.5)$ & NS & NS \\
\hline \multirow[t]{2}{*}{ Inhibitedness } & Intimacy problems & $2.6(0.7)$ & $2.3(0.6)$ & $2.4(0.5)$ & NS & NS \\
\hline & Restricted expression & $3.2(0.5)$ & $2.5(0.5)$ & $2.5(0.6)$ & $p<0.001$ & NS \\
\hline Compulsivity & & $3.5(0.5)$ & $3.3(0.5)$ & $1.2(0.4)$ & $p<0.001$ & $\mathrm{p}<0.001$ \\
\hline
\end{tabular}

with other disorders marked by a GNS vulnerability factor such as borderline personality disorder or mood disorders. This tendency to overly controlled behaviour may play an important role in maladaptive coping with adverse emotional experiences. PNES patients seemed to be characterised by the urge strictly to control overt behaviour while acting out emotional conflicts through seizures and other somatoform symptoms. However, epilepsy patients also showed significantly raised compulsivity scores. It is therefore possible that the experience of having seizures per se causes a tendency to control behaviour very tightly, although there is evidence that the subjective experience of having an epileptic seizure is different from that of having a psychogenic attack. ${ }^{32}$

Our results are in keeping with a study based on the Dutch questionnaire on personality traits describing personality features both in patients with PNES alone and in patients with additional epileptic seizures. ${ }^{27}$ In that study, patients most commonly met diagnostic criteria for borderline, avoidant, and obsessive-compulsive personality disorder.

Given that much of the vulnerability associated with personality pathology is genetically and biologically mediated ${ }^{21}$ these results may have implications for psychotherapeutic treatment: efforts should focus on change of individual adaptation and coping processes rather than on basic tendencies in personality, which are less likely to change. Therapists should promote more adaptive expressions of basic personality traits by increasing the patients' tolerance and acceptance, attenuating pathologic trait expression, and progressively substituting more adaptive trait expression. ${ }^{33}$ For example, patients from cluster 1 can learn how to experience and express their feelings more adequately by social skills training. Patients from cluster 2 may learn more about the real consequences of loss of control, for instance by shame attacking exercises. These are confrontational exercises during which patients expose themselves to an unpleasant situation likely to bring on shame or shame related feelings. They may, for instance, be encouraged to go into a shoe shop, try on 10 pairs of shoes, but then walk out without buying anything.

Moreover, treatment could focus on the modulation of temperamental extremes, recognition of prodromal signs of symptomatic exacerbation, and interruption of such processes of amplification and escalation. The identification and management of stressors or triggers in the (social) environment that interact with personality vulnerability should be emphasised. Elements of these strategies have been integrated in the dialectical behaviour therapy for borderline personality disorder patients, ${ }^{34}$ an approach which can be adapted for PNES patients, particularly from cluster 1 .

Despite its size and the use of an empirical, well validated tool for the assessment of personality, this study has several limitations: The personality data in the study were elicited a mean of 4.1 years after the diagnosis or 11.9 years after manifestation of PNES. Although personality scores have been shown to remain relatively stable in adults, ${ }^{25}$ it is possible that results were affected by therapeutic interventions including psychotropic and anticonvulsant drugs or (further) traumatic experience between the time of diagnosis and this study. There is some evidence that increasing age is associated with an increase in antisocial or histrionic features, and a decrease in impulsive, schizoid, schizotypal, paranoid, obsessional, or avoidant personality features..$^{35}$ We cannot therefore determine with certainty whether a particular personality profile predisposes to the development of PNES. A further drawback associated with the use of self report questionnaires for the assessment of personality is that they do not directly reflect the impression of an individual's thinking or behaviour on others. Although the involvement of a reliable informant is not a requirement for the diagnosis of personality disorders, ${ }^{15}{ }^{37}$ it would certainly be helpful in this context.

In view of the fact that the study was based on a postal survey and that not all patients underwent a standardised psychiatric examination at the time of PNES diagnosis, we have no information on the possible interaction of the personality features described and other psychiatric diagnoses.

A further potential drawback is that the results of cluster analyses are dependent on some arbitrary criteria such as the fusion method used or the cut off to determine the number of clusters. Although the two major clusters seem to be robust, our findings should be replicated in other samples.

Irrespective of these drawbacks, this large comprehensive study shows that maladaptive personality is common in patients with PNES. Such patients can be distinguished from non-clinical controls or patients with epilepsy using a multidimensional tool for the assessment of abnormal personality. However, they do not fall neatly into one of the recognised categories of personality disorder but into one of several clusters with distinct profiles of personality 
pathology. This suggests that-although there may be a limited number of different patient groups-the psychotherapeutic treatment of PNES patients needs to be adapted to each individual's psychopathology and personality profile, and that it is unlikely that one particular psychotherapeutic intervention will be helpful in all cases. The identification of such patient subsets seems clinically relevant because the outcome differed between clusters.

\section{ACKNOWLEDGEMENTS}

This study was supported by the St James's Trust for Nervous System Diseases, the Special Trustees of the General Infirmary at Leeds, UK, and the Verein für die Förderung der Epilepsieforschung e.V. We thank Dr Alex Mitchell for his helpful comments on the manuscript.

\section{Authors' affiliations}

M Reuber, Academic Unit of Neurology, Division of Genomic Medicine, University of Sheffield, Sheffield, UK

R Pukrop, Department of Psychiatry and Psychotherapy, University of Köln, Köln, Germany

J Baver, R Derfuss, C E Elger, Department of Epileptology, University of Bonn, Bonn, Germany

Competing interests: none declared

The study was undertaken at the Department of Epileptology, University of Bonn, Germany

\section{REFERENCES}

1 Lesser RP. Psychogenic seizures. Neurology 1996;46:1499-507.

2 Kuyk J, van Dyck R, Spinhoven P. The case for a dissociative interpretation of pseudoepileptic seizures. J Nerv Ment Dis 1996;184:468-74.

3 Brown RJ, Trimble MR. Dissociative psychopathology, non-epileptic seizures, and neurology [editorial]. J Neurol Neurosurg Psychiatry 2000;69:285-9.

4 Reuber M, Pukrop R, Bauer J, et al. Outcome in psychogenic nonepileptic seizures: 1 to 10 year follow-up in 164 patients. Ann Neurol 2003;53:305-11

5 Kanner AM, Parra J, Frey M, et al. Psychiatric and neurologic predictors of psychogenic pseudoseizure outcome. Neurology 1999;53:933-8.

6 Bowman ES, Markand ON. Psychodynamics and psychiatric diagnoses of pseudoseizure subjects. Am J Psychiatry 1996;153:57-63.

7 Drake ME, Pakalnis A, Phillips BB. Neuropsychological and psychiatric correlates of intractable pseudoseizures. Seizure 1992;1:11-13.

8 Vanderzant CW, Giordani B, Berent S, et al. Personality of patients with pseudoseizures. Neurology 1986;36:664-8.

9 Binder LM, Salinsky MC, Smith SP. Psychological correlates of psychogenic seizures. J Clin Exp Neuropsychol 1994;16:524-30.

10 Kalogiera-Sackellares D, Sackellares JC. Analysis of MMPI patterns in patients with psychogenic pseudoseizures. Seizure 1997;6:419-27.

11 Kalogiera-Sackellares D, Sackellares JC. Personality profiles of patients with pseudoseizures. Seizure 1997;6:1-7.

12 Derry PA, McLachlan RS. The MMPI-2 as an adjunct to the diagnosis of pseudoseizures. Seizure 1996;5:35-40.

13 Storzbach D, Binder LM, Salinsky MC, et al. Improved prediction of nonepileptic seizures with combined MMPI and EEG measures. Epilepsia 2000;41:332-7.
14 Dodrill CB, Holmes MD. Part summary: psychological and neuropsychological evaluation of the patient with non-epileptic seizures. In: Gates JR, Rowan AJ, eds. Non-epileptic seizures. Boston: Butterworth-Heinemann, 2000:169-81.

15 American Psychiatric Association. Diagnostic and statistical manual of mental disorders. Washington, DC: APA, 1994.

16 Widiger TA, Coker LA. Assessing personality disorders. In: Butcher JN, ed. Clinical personality assessment - practical approaches. New York: Oxford University Press, 2002:407-34.

17 Livesley WJ, Schroeder ML, Jackson DN, et al. Categorical distinctions in the study of personality disorder: implication for classification. J Abnorm Psychol 1994; 103:561-5.

18 Widiger TA. The DSM-III-R categorical personality disorder diagnosis: a critique and alternative. Psychol Inquiry 1993;4:75-90.

19 Livesley WJ, Jackson DN. Manual for the dimensional assessment of personality pathology. Port Huron: Sigma Press, 2002.

20 Livesley WJ, Jackson DN, Schroeder ML. Factorial structure of traits delineating personality disorders in clinical and general population samples. J Abnorm Psychol 1992;101:432-40.

21 Livesley WJ, Jang KL, Vernon PA. Phenotypic and genetic structure of traits delineating personality disorder. Arch Gen Psychiatry 1998;55:941-8.

22 Pukrop R. Dimensional personality profiles of borderline personality disorder in comparison with other personality disorders and healthy controls. J Pers Disord 2002; 16:135-47.

23 Pukrop R, Steinmeyer E. Clinical validity of the "Dimensional Assessment of Personality Pathology (DAPP)". In: Rammstedt B, Riemann R, eds. Eleventh European Conference on Personality. Jena: Jena-Abstracts, 2002:56.

24 Costa PT, McCrae RR. Personality disorder and the five-factor model of personality. J Pers Disord 1990;4:362-71.

25 Costa PT, McCrae RR. Stability and change in personality from adolescence through adulthood. In: Halverson CF, Kohnstamm GH, Martin RR, eds. The developing structure of temperament and personality from infancy to adulthood. Hillsdale: Erlbaum, 1994:139-50.

26 Pukrop R, Gentil I, Steinbring I, et al. Factorial structure of the German version of the dimensional assessment of personality pathology-basic questionnaire in clinical and nonclinical samples. J Pers Disord 2001;15:450-6.

27 Kuyk J, Swinkels WAM, Spinhoven P. Psychopathologies in patients with and without comorbid epilepsy: how different are they? Epilepsy Behav 2003;4:13-18.

28 Tyrer P, Seivewright N, Ferguson B. The general neurotic syndrome: a coaxial diagnosis of anxiety, depression and personality disorder. Acta Psychiatr Scand 1992:84:201-6.

29 Andrews G. Comorbidity and the general neurotic syndrome. $\mathrm{Br} J$ s sychiatry 1996;168:76-84.

30 Bass C, Murphy M. Somatoform and personality disorder: syndromal comorbidity and overlapping developmental pathways. J Psychosom Res 1995;39:403-27.

31 Gunderson JG, Zanarini MC, Kisiel CL. Borderline personality disorder. In: Livesley WJ, ed. The DSM-IV personality disorders. New York: Guildford Press, 1995: 141-57.

32 Watson NF, Doherty MJ, Dodrill CB, et al. The experience of earthquakes by patients with epileptic and psychogenic nonepileptic seizures. Epilepsia 2002;43:317-20.

33 Pilkonis PA. Treatment of personality disorders in association with symptom disorders. In: Livesley WJ, ed. Handbook of personality disorders. Theory, research, and treatment. New York: Guilford Press, 2001:541-54.

34 Linehan M. Cognitive-behavioural treatment of borderline personality disorder. New York: Guilford Press, 1993.

35 Seivewright $\mathbf{H}$, Tyrer $\mathrm{P}$, Johnson T. Change in personality status in neurotic disorders. Lancet 2002;359:2253-4.

36 Zuckerman M. Behavioral expressions and biosocial bases of sensation seeking. New York: Cambridge University Press, 1994

37 World Health Organisation. The ICD-10 classification of mental and behavioural disorders: clinical descriptions and diagnostic guidelines. Geneva: WHO, 1992. 